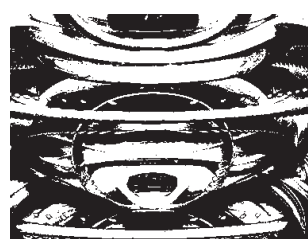

doi:10.5559/di.22.2.08

\title{
PRESUDA PROTIV MILE BUDAKA I DRUŽINE PRONAĐENA JE I OBJAVLJENA
}

Tomislav JONJIĆ

Zagreb

Stjepan MATKOVIĆ

Hrvatski institut za povijest, Zagreb

UDK: $343.919(497.5)^{\prime \prime} 1945^{\prime \prime}(049.2)$

347.95(497.5)"1945":32-051Budak, M.(049.2)

Primljeno: 6. 5. 2013.

Autori odgovaraju na članak dr. sc. Josipa Jurčevića, koji je objavljen u Društvenim istraživanjima br. 4/2012, a u kojemu se tvrdi da nije do sada pronađena presuda Mili Budaku s prvoga poslijeratnog velikog suđenja (1945). U ovome reagiranju autori ispravliaju tu tvrdnju i utvrđuju više nepoznatih činjenica koje se odnose na suđenje Budaku i većem broju visokih dužnosnika Nezavisne Države Hrvatske.

Ključne riječi: Mile Budak, politička suđenja, presuda

$\triangle \quad$ E-mail: tomislav.jonjic@zg.t-com.hr

U svojem inače korisnom radu o djelovanju jugoslavenskih komunističkih vojnih sudova, dr. Josip Jurčević, u kontekstu napomene da su akteri i suvremenici očito sustavno izbjegavali potanje govoriti o toj mračnoj stranici hrvatske i jugoslavenske povijesti, spominje i presudu protiv dr. Mile Budaka. Ne tvrdi pritom da ta presuda ne postoji, nego oprezno - pozivajući se na zbirku članaka o Budaku koju je priredio Darko Sagrak - tvrdi kako "izvorna presuda još nije pronađena" (Jurčević, 2012, str. 1010). U stvarnosti je "presuda protiv M. Budaka" i pronađena i objavljena, a njome nije osuđen samo Budak nego čak deset osoba.

Naime, nakon žurno i vrlo sumarno provedene istrage i saslušanja osumnjičenika bez nazočnosti branitelja, javni tužitelj Hrvatske podigao je 1. lipnja 1945. optužnicu br. K. 68/ 1945. protiv dr. Mile Budaka i devet visokih političkih, pravosudnih i vojnih dužnosnika Nezavisne Države Hrvatske koji 
DRUŠ. ISTRAŽ. ZAGREB GOD. 22 (2013), BR. 2, STR. 369-375

JONJIĆ, T., MATKOVIĆ, $\mathrm{S}$. PRESUDA PROTIV... su bili isporučeni: pukovnika Jurja Juce Rukavine, predsjednika Prijekoga suda dr. Ivana Vidnjevića, predsjednika Hrvatske državne vlade, dr. Nikole Mandića, te ministara dr. Julija Makanca, Nikole Steinfela i dr. Pavla Cankija, kao i ustaškoga doglavnika Ademage Mešića, generala Lavoslava Milića i glavara građanske uprave u oslobođenoj Dalmaciji, dr. Bruna Nardellija. Svima je stavljeno na teret: da su osnovali "protunarodnu terorističko-izdajničku organizaciju 'Ustaša', odnosno naknadno istoj pristupili ili bili sa njom usko povezani", pa su time počinili zločin veleizdaje protiv vlastitog naroda; da su "kao rukovodioci, prvaci, podstrekači, pomagači (...) inspirirali, organizirali i sudjelovali u izvršenju" velikoga broja zločina, od kojih je znatan broj poimence, ali vrlo općenito, naveden (Petrinović, 2002).

Vojdrag Berčić, koji je kao nesvršeni student prava bio istražitelj i Budaku i Mandiću, ustvrdio je kasnije da su svi optuženici imali "svoje odvjetnike" (Rašeta, 2004, str. 46-47). Ta je tvrdnja uglavnom netočna. Osumnjičenici nisu imali branitelje tijekom istrage, a ni pošto je optužnica podignuta, njihovo se pravo na obranu nije poštovalo. Poznati zagrebački odvjetnik dr. Ivo Politeo u svojim nedatiranim, ali očito naknadnim, bilješkama zapisao je: "Dana 30. svibnja 1945. obaviješten o izboru braniteljem, 1. lipnja primio optužnicu, pročitao nju i spise i imao opći zajednički razgovor u zatvoru sa svim optuženicima (osam, odnosno devet). Rasprava 2. lipnja nije započela, jer je odgođena zbog nezgode jednoga člana vijeća." (HR-HDA-416, Odvjetnička pisarnica Ivo Politeo, k. 3, spis: Mile Budak - proces 1945., nereg. i Štajduhar, 2002). Iz toga proizlazi da je Politeo branio najmanje osam, a vjerojatno čak devet od ukupno deset optuženika. I pravno neukoj osobi posve je jasno da su time prekršena njihova osnovna prava, jer su njihovi interesi mogli biti (a nesumnjivo i jesu bili) bar u djelomičnoj koliziji, pa ih nipošto nije smio braniti jedan branitelj, čak i da mu je ostavljeno dovoljno vrijeme za pripremu.

U svojim bilješkama Politeo ne spominje nikakve kasnije konzultacije s bilo kojim od optuženika nakon toga petka, 1 . lipnja 1945., nego navodi da je "petoga lipnja obaviješten da će sutra biti rasprava" (HR-HDA-416, Politeo). Zato možemo samo nagađati je li mu daljnja priprema obrane u dogovoru s branjenicima onemogućena (što je prilično vjerojatno kad se ima na umu da su Politeove konzultacije s nadbiskupom dr. Alojzijem Stepincem godinu i pol kasnije bile također vrlo ograničene), ili ju je on sam smatrao nepotrebnom.

Glavna rasprava doista je i održana toga 6. lipnja, ali nije sasvim jasno tko je zastupao optužbu. Član sudskoga vijeća Gabro Divjanović nimalo ne dvoji oko toga da je tužitelj na glavnoj raspravi bio upravo Jakov Blažević, pa dodaje da je on, skupa s Josipom Hrnčevićem, vodio "sve u vezi suđenja 
DRUŠ. ISTRAŽ. ZAGREB GOD. 22 (2013), BR. 2, STR. 369-375

JONJIĆ, T., MATKOVIĆ, S.: PRESUDA PROTIV...
Budaku i drugim ustaškim ministrima" (Tuđen, 1990). I Berčić tvrdi da je optužnicu zastupao Blažević, a da mu je asistirao Drago Desput (Hudelist, 2003). Iz Politeovih bilježaka također proizlazi da je tužitelj na glavnoj raspravi bio Blažević (HR-HDA-416, Politeo, k. 3). Međutim, iako se u Tanjugovu izvješću sa suđenja, objavljenom 7. lipnja u jugoslavenskom tisku, citiraju oštre optužbe i replike koje je optuženicima i obrani upućivao javni tužitelj Blažević, on je nakon 1990. izričito poricao da je zastupao optužbu u tom predmetu (Štajduhar, 2000). Još zanimljivije je da je petnaestak godina ranije tvrdio kako Budak i družina uopće nisu suđeni u Zagrebu nego pred Vojnim sudom Generalštaba Jugoslovenske armije u Beogradu. U skladu s time, u svoju knjigu - u koju su uvršteni njegovi tužiteljski govori s velikih poratnih postupaka - nije unio baš ništa skopčano sa suđenjem Budaku i družini (Blažević, 1976, str. 120 i dr.). Doista je teško objasniti takve Blaževićeve tvrdnje, jer je proces Budaku i nekolicini najviših dužnosnika NDH bio u političkom pogledu prvi i najvažniji poratni proces sve do suđenja nadbiskupu Stepincu, a Blažević je u vrijeme objavljivanja svoje knjige, pa i kasnije, dao čitav niz izjava i razgovora u kojima je zastupao stajališta što nedvoumno potvrđuje da se svoje poratne tužiteljske uloge nije sramio niti je o njoj izbjegavao govoriti.

Glavna rasprava u postupku protiv Budaka i ostalih provedena je iznimnom brzinom, bez ozbiljnog izvođenja dokaza i saslušanja svjedoka. Ovako ju je u svojim kasnijim bilješkama opisao Politeo: "Šestoga lipnja 1945. rasprava od osam ujutro do 13,30, nastavak u 15 sati, svršetak oko 20, proglašenje oko 20,40, čitanje presude od 20,40 do 21,15. Predsjedao sudski pukovnik Hrnčević, članovi vijeća major Divjanović i kapetan Ranogajec. Javni tužilac Jakov Blažević." (HR-HDA-416, Politeo, k. 3). Naravno, osuda se znala unaprijed. Član sudskoga vijeća Gabrijel Divjanović izjavio je šezdesetak godina kasnije kako se ne sjeća da je uopće čitao spis, dodajući da on ionako nije "imao osobitih ingerencija" i da je Budaku postavio "nekoliko pitanja više reda radi" (Tuđen, 1990; Sagrak, 2006, str. 481-483).

O tome kako je doista teklo suđenje još rječitije i očito preciznije od njegovih kasnijih bilježaka govori jedno Politeovo pismo iz srpnja 1946. godine. To je pismo napisano, dakle, malo više od godine dana nakon suđenja, dok je Politeovo sjećanje bilo još svježe. Na početku srpnja 1946. on je, naime, primio pismo koje mu je 27. lipnja te godine uputio splitski odvjetnik dr. Ivo Tartaglia. U pismu je stajalo: "Dragi kolega Politeo. Gđa Rita Nardelli, čijeg ste supruga vi branili na kaznenoj raspravi pred Vojnim sudom u Zagrebu, zamolila me da joj sastavim molbu za pomilovanje. Obećao sam da ću to učiniti, ne kao odvjetnik, već kao 'prijatelj i čovjek'. Ali Rita Nardelli 
DRUŠ. ISTRAŽ. ZAGREB GOD. 22 (2013), BR. 2, STR. 369-375

JONJIĆ, T., MATKOVIĆ, S.: PRESUDA PROTIV... nema nikakvih podataka o postupku, pa me uputila da vas zamolim da mi date barem najnužnije podatke, koji je naslov suda, ako imate optužnicu i osudu, pošaljite mi to, kako bih imao podatke kome treba uputiti molbu."

Na tu je molbu Politeo odvratio pismom od 1. srpnja 1946., u kojem navodi da molbi može tek djelomično udovoljiti: "O zatraženoj presudi mogu Vam vrlo malo saopćiti, jer nisam mogao držati ni jednu ispravu, pače ni optužnicu, u koju sam imao samo uvid do konca procesa. Sudio je Vojni sud II. Armije dne 6. lipnja p. g. Rasprava protiv sve desetorice trajala je od jutra 8 sati do navečer 9 sati, kada je presuda samo proglašena, ali mi pismeno nije saopćena. Prema tome neznam ni oznaku spisa. Suđeni su zbog djela veleizdaje i ratnog zločinstva po Vojnom zakonu, i to Nardelli na kaznu robije u trajanju od 20 godina i na trajan gubitak građanske časti i konfiskaciju imovine. Optužilo ga se što je kao građanski glavar Dalmacije i kasnije funkcionar ministarstva vanjskih poslova [!] surađivao s okupatorom i njegovim pomagačima. Branio se prisilom i upornim nastojanjem, da što više spriječi i umanji (...) koja su prijetila narodu od drugih. Detalja inkriminacije ne mogu se sjetiti, mislim, da ih nije bilo mnogo i da nisu važni, jer je za osudu dostajala gore (...)menuta činjenica o njegovu odnosu prema ustašama i okupatoru.

Mislim da vam je za molbu za pomilovanje to dovoljno jer se u njoj ionako ne možete upuštati u ocjenu suda, a olakotne okolnosti i razloge dostojnosti pomilovanja i onako će vam reći osuđenikova gospođa." (HR-HDA-416. Odvjetnička pisarnica Ivo Politeo. Rukopisna ostavština I. Politeo, k. 16, spis: Nardelli (Bruno) Rita).

Iz toga jasno proizlazi da Politeo - kao branitelj većine optuženika - nije imao na raspolaganju ni optužnice ni presude, a nije znao čak ni broj spisa, iz čega proizlazi da nije dobio ni zapisnik s glavne rasprave, jer bi u zapisniku nužno bio naveden i broj spisa. Optužnicu je ipak čitao. Pritom je nemoguće sa sigurnosti ustanoviti je li mu optužnica s popisom dokaza uručena 1. lipnja 1945., pa ju je on imao u posjedu bar do okončanja glavne rasprave 6. lipnja, ili mu je ipak uručena tek $\mathrm{u}$ sudnici, pa ju je morao vratiti istoga dana. Vjerojatnijim se čini potonje, jer da je Politeo optužnicu imao punih šest dana, ne bi bilo razumno da je vlasti traže natrag, jer ju je on u tom razdoblju lako mogao fotografirati ili načiniti njezin prijepis.

U svakom slučaju, iz toga bez ikakve dvojbe proizlazi da ni Politeo ni Nardelli, odnosno njegova supruga, ni na početku ljeta 1946. nisu raspolagali pismenim otpravkom presude. To ipak ne znači da on nije načinjen, iako je očito načinjen znatno nakon okončanja suđenja.

Jugoslavenski komunistički Vjesnik objavio je 7. lipnja 1945. da je Vojni sud II. armije dan ranije u Zagrebu osudio "veleiz- 
DRUŠ. ISTRAŽ. ZAGREB GOD. 22 (2013), BR. 2, STR. 369-375

JONJIĆ, T., MATKOVIĆ, S.: PRESUDA PROTIV... dajničku i zločinačku bandu dr. Milu Budaka i ostale ustaške glavešine". U vijesti se navodi kako su "zbog veleizdaje i ratnih zločina" osuđeni na smrt vješanjem, trajan gubitak građanske časti i konfiskaciju imovine dr. Mile Budak, pukovnik Joso (sic!) Rukavina, predsjednik Prijekoga suda dr. Ivan Vidnjević; na smrt strijeljanjem, trajan gubitak građanske časti i konfiskaciju imovine predsjednik ustaške vlade dr. Nikola Mandić, ministar dr. Julije Makanec, ministar Nikola Steinfel i ministar dr. Pavao Canki, dok je na kaznu doživotne robije osuđen ustaški doglavnik Ademaga Mešić, a general Lavoslav Milić i "ustaški guverner Dalmacije" dr. Bruno Nardelli na kaznu robije u trajanju od 20 godina. I potonjoj trojici izrečena je mjera trajnoga gubitka građanske časti te konfiskacija imovine (Vjesnik, 1945, br. 41). Sutradan je isti list objavio opširniji, nepotpisani komentar te osude "ustaških zločinaca, doglavnika, ministara i funkcionara", ukratko donoseći navode "iz teške optužnice koju je podnio javni tužilac Hrvatske Jakov Blažević" te se izrugujući optuženicima zbog kukavičkoga držanja i prebacivanja odgovornosti na druge. Jedino je L. Milić, piše Vjesnik, priznao odgovornost i čak počeo plakati (Vjesnik, 1945, br. 42). Iz Politeovih bilježaka, međutim, ne proizlazi da bi se optuženici držali "kukavički".

Osim što nisu dobili presudu, nema nikakve dvojbe da optuženici nisu imali ni pravo na žalbu. Berčić je, doduše, ustvrdio da su svi optuženici, osim Vidnjevića, htjeli izjaviti žalbu (Hudelist, 2003, 89). No za to nije bilo ni vremena ni mogućnosti, jer postupak nije ni bio dvostupanjski, a $\mathrm{k}$ tome bi žalba pretpostavljala pravodobnu izradbu pisanog otpravka presude. Ipak je moguće da su optuženici (ili bar dio njih) pokušali tražili pomilovanje. Po navodima Gabrijela Divjanovića, svi optuženici, osim Vidnjevića, to su i učinili (Tuđen, 1990). No ni za ovo nema nikakva dokaza: nikad nije pronađen nikakav pisani trag ni navodne molbe za pomilovanje, a ni odluke o njoj, pa se može samo nagađati je li molba u noći sa 6 . na 7. lipnja 1945. uopće upućena i je li u vezi s njom donesena ikakva odluka. Nije pronađen ni zapisnik s glavne rasprave ni zapisnik o vijećanju. A kako proizlazi iz Tanjugove vijesti od 7. lipnja, osuda nad osuđenima na smrt izvršena je u ranim jutarnjim satima 7. lipnja 1945. godine (Krizman, 1986; Jareb, 1990). Prema objavljenoj osudi, M. Budak je trebao biti obješen. Međutim, prema rukopisnome popisu smrtnih presuda Vojnog suda Komande zagrebačkoga područja, koji obuhvaća razdoblje od 12. svibnja 1945. do 22. veljače 1946., osuda nad njim izvršena je strijeljanjem ("Smrtne presude Vojnog suda Komande zagrebačkog područja", u: Partizanska i komunistička represija i zločini u Hrvatskoj 1944.-1946. Dokumenti: Zagreb i središnja Hrvatska, 2008). 
DRUŠ. ISTRAŽ. ZAGREB GOD. 22 (2013), BR. 2, STR. 369-375

JONJIĆ, T., MATKOVIĆ, S.: PRESUDA PROTIV...

\section{IZVORI}

\section{LITERATURA}

Ukratko, budući da ni trinaest mjeseci kasnije, potkraj lipnja 1946., supruga B. Nardellija ni njegov branitelj nisu raspolagali presudom, pa čak ni njezinim brojem, može se s velikim stupnjem sigurnosti zaključiti da osuđenicima pismeni otpravak osude nikad nije uručen. Ona je očito izrađena naknadno, dugo nakon egzekucije osuđenih na smrt, i to najvjerojatnije za potrebe postupka konfiskacije imovine osuđenika, a ne za potrebe kaznenoga postupka. No presuda je sačuvana $\mathrm{u}$ najmanje dva primjerka. Jedan prijepis sačuvan je u Državnome arhivu u Zagrebu, $\mathrm{u}$ fondu koji se odnosi na konfiskacije i to u spisu Nikole Mandića (DAZ, kut. 472). U istome spisu nalazi se podatak da se u Budakovu kuću na Josipovcu br. 19 uselio predsjednik ZAVNOH-a Vladimir Nazor te popis svih zatečenih predmeta pronađenih u toj kući, kao i u kući obitelji Budak u Rimu br. 98 s pripadajućom gospodarskom zgradom. Drugi primjerak presude protiv M. Budaka i družine nalazi se $\mathrm{u}$ Hrvatskome državnom arhivu, $\mathrm{u}$ fondu Javnog tužiteljstva (HR-HDA, fond Javno tužiteljstvo, kut. 130). Ona je i objavljena dvije godine nakon što je nastala Sagrakova zbirka tekstova o Budaku, odnosno pune četiri godine prije Jurčevićeva članka. Pod naslovom "Presuda Vojnog suda II. Jugoslavenske armije u Zagrebu visokim dužnosnicima NDH dr. Mili Budaku i dr." (dok. 115, str. 417.-422.) u svoj zbornik dokumenata Partizanska $i$ komunistička represija i zločini u Hrvatskoj 1944.-1946. Dokumenti: Zagreb i središnja Hrvatska uvrstili su je priređivači zbornika: Vladimir Geiger, Mate Rupić, Mario Kevo, Egon Kraljević i Zvonimir Despot.

Državni arhiv u Zagrebu (DAZ): fond Narodni odbor grada Zagreba, dosje Mandić, Kotarski sud Zagreb, spis Mile Budak, kut. 472. Hrvatski državni arhiv (HDA): fond Javno tužiteljstvo, Presuda Mili Budaku i drugima, kut. 130.

HDA: 416 - fond Odvjetnička pisarnica Ivo Politeo, k. 3, spis: Mile Budak - proces 1945., nereg.

Partizanska i komunistička represija i zločini u Hrvatskoj 1944.-1946. Dokumenti: Zagreb i središnja Hrvatska (2008), prir. V. Geiger i sur., Zagreb-Slavonski Brod: Hrvatski institut za povijest, Podružnica za povijest Slavonije, Srijema i Baranje, dok. 90., str. 347.

Blažević, J. (1976). Tražio sam crvenu nit. Zagreb: "Zagreb".

Hudelist, D. (2003, 1. kolovoza). Partizanski malj za ustaške ministre. Razgovor s Vojdragom Berčićem. Globus, 14(br. 660), 82-89.

Jareb, J. (1990). Prilog životopisu Dra Mile Budaka (Sv. Rok, Lika, 30. kolovoza 1889. - Zagreb, 7. lipnja 1945.), Mile Budak: pjesnik i mučenik Hrvatske. U V. Nikolić (ur.), Spomen-zbornik o stotoj godišnjici rođenja 1889-1989 (knj. XVI, str. 21-95). Barcelona - München: Knjižnica Hrvatske revije. 
DRUŠ. ISTRAŽ. ZAGREB GOD. 22 (2013), BR. 2 STR. 369-375

JONJIĆ, T., MATKOVIĆ, S.: PRESUDA PROTIV...
Jurčević, J. (2012). Osnovne značajke presuda jugoslavenskih komunističkih vojnih sudova u Hrvatskoj 1944. i 1945. Društvena istraživanja, 21(4), 1007-1026. doi:10.5559/di.21.4.10

Krizman, B. (1986). Pavelić u bjekstvu. Zagreb: Globus.

Osudjena veleizdajnička i zločinačka banda dr Mile Budak i ostale ustaške glavešine. (7. lipnja 1945.). Vjesnik, 5/1945, br. 41, str. 1.

Petrinović, I. (2002). Mile Budak - portret jednog političara. Split: Književni krug.

Rašeta, B. (2004, 14. svibnja). Proces ustaškoj vladi (2). Pavelić se divio Nemanji. Feral Tribune, 20(br. 973), 46-47.

Sagrak, D. (2006). Mile Budak o sebi, i drugi o njemu. Zagreb: Naklada Darko Sagrak.

Štajduhar, M. (2000, 9. lipnja). Pisac bez groba. Godišnjica smrti Mile Budaka. Fokus, 1(br. 5), 62.

Tuđen, B. (1990, 29. rujna). Čovjek koji je sudio Budaku, razgovor s dr. Gabrijelom Divjanovićem, predratnim lijevim HSS-ovcem, načelnikom vojnosudskog odjeljenja glavnog štaba Hrvatske i zatočenikom Golog otoka. Večernji list, 34(br. 9739), 8.

Veleizdajnike i ustaške ratne zločince stiže zaslužena kazna narodne pravde. (8. lipnja 1945.). Vjesnik, 5/1945, br. 42, str. 1.

\section{The Verdict against Mile Budak and his Associates Has Been Discovered and Published}

Tomislav JONJIĆ

Zagreb

Stjepan MATKOVIĆ

Croatian Institute of History, Zagreb

This text presents a reaction to the article by Josip Jurčević, published in the journal Društvena istraživanja no. 4/2012, in which he claims that the verdict from the first big post-war trial in 1945 against Dr. Mile Budak does not exist. The authors of this article correct Jurčević's statement and disclose some previously unknown information concerning Budak's trial, which was also the trial of other higher administrative officials within the apparatus of the Independent State of Croatia.

Keywords: Mile Budak, political trials, verdict 